\title{
8
}
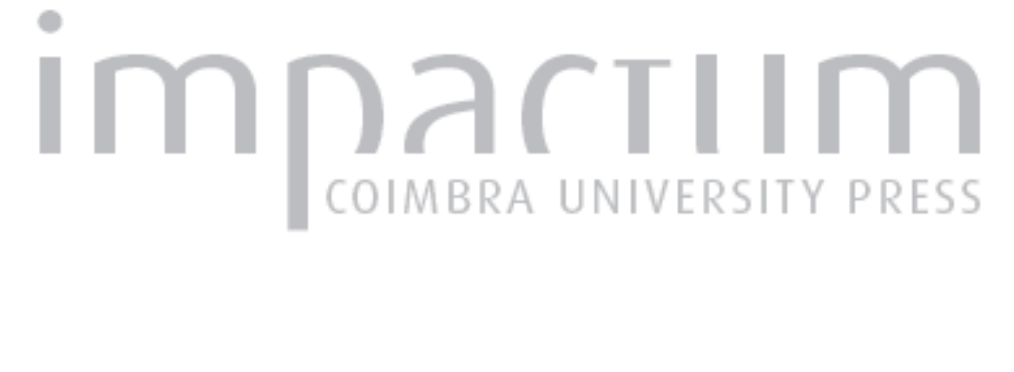

\section{Cerâmica da II Idade do Ferro de Aeminium - R. Fernandes Tomás 72/74 (Coimbra,} Portugal)

\author{
Autor(es): $\quad$ Almeida, Sara Oliveira; Nóbrega, José Ricardo; Vilaça, Raquel; Silva, \\ Ricardo Costeira da
}

Publicado por: Faculdade de Letras da Universidade de Coimbra

URL

persistente:

URI:http://hdl.handle.net/10316.2/35091

DOI:

DOI:http://dx.doi.org/10.14195/1647-8657_50_2

Accessed : $\quad$ 26-Apr-2023 12:31:38

A navegação consulta e descarregamento dos títulos inseridos nas Bibliotecas Digitais UC Digitalis, UC Pombalina e UC Impactum, pressupõem a aceitação plena e sem reservas dos Termos e Condições de Uso destas Bibliotecas Digitais, disponíveis em https://digitalis.uc.pt/pt-pt/termos.

Conforme exposto nos referidos Termos e Condições de Uso, o descarregamento de títulos de acesso restrito requer uma licença válida de autorização devendo o utilizador aceder ao(s) documento(s) a partir de um endereço de IP da instituição detentora da supramencionada licença.

Ao utilizador é apenas permitido o descarregamento para uso pessoal, pelo que o emprego do(s) título(s) descarregado(s) para outro fim, designadamente comercial, carece de autorização do respetivo autor ou editor da obra.

Na medida em que todas as obras da UC Digitalis se encontram protegidas pelo Código do Direito de Autor e Direitos Conexos e demais legislação aplicável, toda a cópia, parcial ou total, deste documento, nos casos em que é legalmente admitida, deverá conter ou fazer-se acompanhar por este aviso.

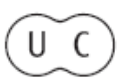




\section{CONIMBRIGA}

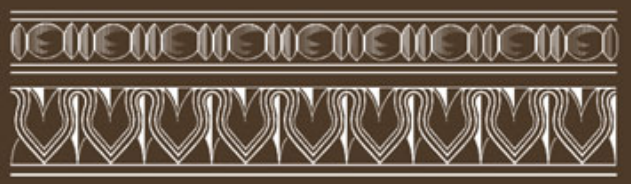

INSTITUTO DE ARQUEOLOGIA

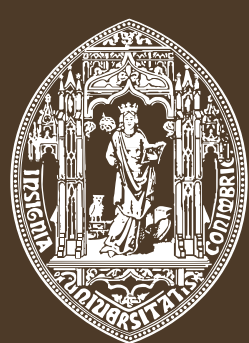

VOLUME L・2011

FACULDADE DE LETRAS UNIVERSIDADE DE COIMBRA 
Sara Oliveira Almeida

Gabinete para o Centro Histórico - Câmara Municipal de Coimbra

José RicARdo NóBrega

Responsável científico pela intervenção

Raquel VilaÇa

Centro de Estudos em Arqueologia, Artes e Ciências do Património (CEAACP)

Instituto de Arqueologia FLUC

Ricardo Costeira da Silva

Bolseiro de doutoramento da Fundação para a Ciência e Tecnologia (FCT)

Centro de Estudos em Arqueologia, Artes e Ciências do Património (CEAACP)

CERÂMICA DA II IDADE DO FERRO DE AEMINIUM

- R. FERNANDES TOMÁS 72/74 (COIMBRA, PORTUGAL)

LATE IRON AGE POTTERY OF AEMINIUM

- 72/74 FERNANDES TOMÁS STREET (COIMBRA, PORTUGAL)

"Conimbriga" L (2011) p. 33-57

Resumo: A recuperação de um conjunto cerâmico em contextos atribuíveis à II Idade do Ferro, no âmbito de uma intervenção arqueológica em Coimbra, possibilita uma primeira abordagem à cultura material anterior ao domínio romano deste local. Embora se conheça mal a produção artefactual desta época no contexto regional envolvente, este lote parece espelhar uma forte matriz indígena, no que se refere ao léxico formal, revelando, contudo, marcas do contacto com esferas civilizacionais longínquas.

Palavras-chave: Coimbra; II Idade do Ferro; cerâmica.

ABstract: The gathering of ceramic artifacts in a setting of the Late Iron Age, within an archaeological excavation in Coimbra, allows a first approach to the material culture prior to the Roman domain of this territory.

Conimbriga, 50 (2011) 33-57 
Although we barely know the pottery manufacturing for this time in the regional context, this group appears to reflect a strong native component with respect to the formal lexicon, however revealing marks of contact with distant civilization spheres.

Keywords: Coimbra (Portugal); Late Iron Age; pottery. 


\section{CERÂMICA DA II IDADE DO FERRO DE AEMINIUM - R. FERNANDES TOMÁS 72/74 (COIMBRA, PORTUGAL)}

\section{Introdução}

A construção do discurso histórico em torno da origem de Coimbra revela-se, forçosamente, um processo em curso e aberto à incorporação de novos dados ou à reinterpretação da narrativa vigente.

Neste sentido, e concretizando a ideia precedente, aos elementos de carácter "avulso" recolhidos em deposição secundária, em diversos pontos do núcleo urbano antigo (Mantas, 1983 e 1992; Frade e Caetano, 1994, 328; Carvalho, 1998; Filipe, 2006, 341), soma-se a identificação de um lote artefactual, recentemente descoberto no âmbito de uma intervenção arqueológica de salvaguarda e proveniente de contextos que precedem a integração deste espaço no território da república romana.

O presente texto faz precisamente eco deste achado, ensaiando uma aproximação ao repertório cerâmico identificado, o mais representativo em termos numéricos e informativos, até ao momento, do período sidérico de Aeminium.

\section{A escavação}

Em 2006, no contexto da aplicação do plano de avaliação e diagnóstico patrimonial referente à reabilitação do imóvel $n^{\circ} 72$ e 74 da Rua Fernandes Tomás (Fig. 1), realizou-se um conjunto de sondagens arqueológicas prévias, da responsabilidade de um dos signatários (JRN) ${ }^{1}$.

${ }^{1}$ Em co-direcção com Luís Miguel dos Santos Reis. Registou-se subsequentemente uma intervenção de acompanhamento da obra dirigida por Jorge Pinho, de cujos resultados se aguarda a publicação.

Conimbriga, 50 (2011) 33-57 
O imóvel em questão inscreve-se já no perímetro limítrofe do centro histórico muralhado, que se confunde com a "Alta", de Coimbra. Corresponde, esta, a uma elevação formada por arenitos e calcários, escarpada, com encostas íngremes a norte, oeste e sul, peculiarmente fendida a meio pela torrente do "quebra-costas" e conformada pelas linhas de água de Balneis Regis e do Botânico (Margarido, 1987). Muito embora as transformações na modelação do terreno ocorridas ao longo do tempo tenham contribuído para atenuar o declive original do local, é ainda perceptível como a orografia proto-histórica se deveria aproximar do modelo de esporão fluvial. Ora, o local da intervenção fixa-se num ponto imediatamente sobranceiro ao rio e onde o terreno revela um acentuado desnível altimétrico, não sendo casual que se tenha traçado por aqui ulteriormente a linha de muralha da Cidade (Alarcão, 2008) (Fig. 2).

No decurso dos referidos trabalhos foi possível identificar, em duas das sondagens ( 1 e 2 - perfazendo $\left.14 \mathrm{~m}^{2}\right)$, níveis estratigráficos de formação pré-romana (cf. corte estratigráfico - Fig. 4). Este pacote estratigráfico era composto por uma sequência de depósitos sedimentares, cuja configuração respeita o pendor do substrato geológico e vestígios de um possível nível de circulação [est. 3]. Selava os níveis mencionados um pavimento, datado do período romano [est. 2], encontrando-se ambos cortados a poente para permitir a edificação do pano de muralha identificado no tardoz do edifício [est. 1] ${ }^{2}$ (Fig. 3 e 4$)$.

A natureza destes estratos não é completamente segura, podendo, pela localização, corresponder a terras de despejo ou depósitos formados por fenómenos de escorrência e lixiviamento. No entanto, a identificação da estrutura 3 (empedrado) e o facto da cerâmica recolhida não apresentar fracturas particularmente erodidas afasta esta segunda hipótese. Portanto, apesar de distar aproximadamente $500 \mathrm{~m}$ do topo da "Acrópole", e apresentar relativamente a esta um desnível de $60 \mathrm{~m}$ de altitude, admite-se, para já, a possibilidade da mancha de ocupação do povoado da Idade do Ferro se estender pelo menos até este ponto do terreno.

${ }^{2} \mathrm{O}$ estudo desta estrutura defensiva encontra-se em preparação.

Conimbriga, 50 (2011) 33-57 


\section{Análise do Espólio Cerâmico}

Do espólio ${ }^{3}$ recolhido nos níveis pré-romanos da intervenção, dá-se destaque ao material cerâmico (1317 fragmentos [578 Sond $1+739$ Sond 2]), que constitui o maior conjunto artefactual proto-histórico, conhecido até ao momento em Coimbra.

A presunção da relativa contemporaneidade de formação dos depósitos sedimentares em causa, assente no facto de não se haver detectado diferenças significativas ao nível do registo material exumado nas sucessivas unidades estratigráficas (tendo-se verificado colagens de fragmentos entre camadas - o que aponta para uma formação dos depósitos num curto espaço de tempo) e entre as sondagens, permitiu que se analisasse o lote de forma global. Neste sentido, e considerando a dimensão do conjunto, entendeu-se esta como a forma mais adequada ao estabelecimento de um quadro mínimo de referência cultural.

Em termos globais, o conjunto encontra-se bastante fragmentado, equivalendo maioritariamente a bojos $(88 \%)$, registando-se em menor percentagem outros componentes morfológicos (12\% - 112 fragmentos de bordo, 48 fragmentos de fundo e 9 asas). Assinala-se ainda a escassa presença de decoração ( $1 \%$ da amostra - 11 fragmentos).

Atendendo aos aspectos técnicos, constata-se que $92 \%$ dos fragmentos são produzidos manualmente, $2 \%$ produzidos com auxílio a torno e em $6 \%$ da amostra é difícil precisar a técnica empregue.

Para a caracterização das pastas (compacticidade, textura, calibre e frequência de elementos não plásticos (e.n.p.), a observação macroscópica das fracturas permitiu individualizar três grupos tecnológicos principais.

O mais comum (68\% dos fragmentos) corresponde a fabrico de qualidade mediana (com pastas compactas e presença moderada de e.n.p. até $1,5 \mathrm{~mm}$ ). A porção de fragmentos com fabrico fino atinge $19 \%$ do conjunto e define-se por pastas compactas, com reduzida frequência de e.n.p. de pequeno calibre (até $0,5 \mathrm{~mm}$ ), por vezes sem distinção visual. Por último, $13 \%$ do conjunto mostra fabrico grosseiro (com pastas medianamente a pouco compactas com frequentes a abundantes e.n.p. $>1 \mathrm{~mm})$.

${ }^{3}$ Para além do espólio cerâmico, regista-se um fragmento de conta em pasta vítrea azul gelo e pequenos fragmentos amorfos em bronze. Assinala-se ainda um conjunto de fauna mamalógica, onde se regista a presença de caprídeos, bovídeos e equídeos (inf. de Vera Pereira, doutoranda na FLUC, a quem agradecemos a colaboração).

Conimbriga, 50 (2011) 33-57 
À excepção dos fabricos finos, os restantes denunciam, quase exclusivamente, modelação manual. No que concerne aos fabricos finos, $57 \%$ dos fragmentos deste grupo evidenciam modelação manual e 16\% modelação com apoio de torno. Neste grupo, devido ao polimento intenso das superfícies, que dificulta a percepção das estrias de rotação, não foi possível averiguar a técnica de modelação em $27 \%$ dos exemplares.

Independentemente dos fabricos acima tipificados, a observação efectuada aponta para uma matriz comum das pastas e para a presença regular dos mesmos e.n.p. ${ }^{4}$. Dentre estes predominam os grãos de quartzo e palhetas de mica, a que se adicionam regularmente nódulos ferruginosos, partículas orgânicas e grog (normalmente dentro de um intervalo de calibre entre os 0,5 e $1 \mathrm{~mm}$ ). Esta matriz comum confere ao conjunto uma coerência técnica indiciadora da procedência local ou regional do mesmo.

A coloração das pastas permite atribuir a $35 \%$ do conjunto cozedura oxidante. Quanto ao ambiente de cozedura da amostra remanescente apenas se pode afirmar que $33 \%$ dos fragmentos ostenta pastas em tons de castanho e $32 \%$ em tons de cinzento.

A coloração das superfícies evidencia alguma variabilidade (inclusive na mesma peça), sendo sobretudo registadas as combinações de castanhos (35\%), de colorações escuras - cinza/negro - (19\%) e de laranjas $(16 \%)$ nas faces interna e externa. Sucedem-se, com menor representatividade, as combinações de cinzentos/negros no interior com castanhos no exterior (11\%). As restantes combinações são estatisticamente pouco expressivas.

Ainda no que se refere às características tecnológicas, a variabilidade detectada dentro do tipo de fabrico denominado fino, acusou a convivência de realidades distintas e merecedoras de individualização no seio destas produções de qualidade mais elevada.

Assim, assinalam-se os seguintes grupos dentro das produções de fabrico fino:

F.A.: Fabrico caracterizado por pastas depuradas, geralmente com cozeduras oxidantes -rosadas/laranja - $(66 \%)$, por vezes oxidantes com arrefecimento redutor (7\%) e superfícies revestidas por aguada negra. Pelo menos uma das faces (normalmente a externa) mostra-se intensamente polida e mais raramente espatulada (espatulamento de

${ }^{4}$ A análise de lâminas delgadas referentes aos diferentes fabricos confirma este facto (inf. de Ana Osório, doutoranda da FLUC, a quem agradecemos a colaboração).

Conimbriga, 50 (2011) 33-57 
sentido horizontal) adquirindo um aspecto muito brilhante e uniforme simulando o verniz negro. Na maioria dos exemplares estudados o tipo de modelação não é evidente. Regista-se, porém, a presença significativa de produções com recurso a torno (21\%) face às manuais $(27 \%)$. Quando há distinção visual de e.n.p., assinala-se a inclusão de quartzo, nódulos ferruginosos, mica, grog e partículas orgânicas de pequeno calibre $(<0,5$ $\mathrm{mm}$ ). A espessura das paredes é reduzida, com valores entre os $0,25 \mathrm{e}$ $0,7 \mathrm{~mm}$. Corresponde a $27 \%$ dos fragmentos de fabrico fino.

F.B.: Fabrico associado a pastas depuradas, de colorações variadas (dos cinzas aos laranjas) com presença de e.n.p. de pequeno calibre (quartzo, mica, nódulos ferruginosos, grog e partículas orgânicas). No que respeita ao ambiente de cozedura, 33\% da amostra acusa um ambiente oxidante. As superfícies, normalmente envolvidas com aguada, apresentam colorações cinzentas, que podem derivar em tons de castanho e bege, ostentam uma das faces intensamente polida (normalmente a externa) ou excepcionalmente espatulada. Cerca de metade do conjunto revela modelação manual, $28 \%$ ao torno e em $27 \%$ não foi possível determinar o tipo de modelação. Associam-se-lhe peças de pequena dimensão com um intervalo de espessura das paredes entre os 0,35 e $0,8 \mathrm{~mm}$. Representa $29 \%$ do fabrico fino e equivale, na sua maioria, ao que convencionalmente se designa como cerâmica cinzenta fina.

F.D.: Fabrico identificado num reduzido número de exemplares (3\%), com pastas homogéneas, bem depuradas com fraca presença de e.n.p. (quartzo, mica, nódulos ferruginosos) de pequeno calibre $(<0,5$ $\mathrm{mm}$ ) produzidos em ambiente oxidante. A característica mais distintiva deste sub-grupo é a coloração laranja-vivo das superfícies que ostentam um tratamento cuidado (polimento). Em metade do grupo observa-se uma produção ao torno, enquanto no restante o polimento das superfícies dificulta a determinação do tipo de modelação.

F.E.: Fabrico com qualidade técnica inferior aos anteriores, com tratamentos superficiais menos esmerados e modelação manual. As pastas assemelham-se às do fabrico F.B. Representa $41 \%$ das produções finas.

Para a classificação tipológica dos recipientes, o escasso número mínimo de indivíduos recuperados (NMI: 112), a reduzida reconstituição formal e fisionomia geral dos mesmos, aconselhou a escolha de um modelo tipológico definido com base em critérios exclusivamente formais. Para além disso, a dificuldade em reunir linhas de perfil completas cingiu a selecção a um número restrito de tipos morfológicos.

Conimbriga, 50 (2011) 33-57 
Nestas circunstâncias, e atendendo aos indivíduos com maior potencial informativo, destaca-se a preponderância das formas fechadas $(96 \%)$ relativamente às abertas que assumem uma expressão meramente vestigial (4\%).

A listagem dos tipos morfológicos identificados revela simplicidade e monotonia formal como principais atributos do lote. Neste, o elenco tipológico reduz-se a quatro formas básicas, três das quais diferenciadas sobretudo por variações de escala.

\section{Tipo I (Pote)}

Consiste no formato mais frequente (NMI: 29) definido como recipiente fechado de médias dimensões (diâmetros de bordo entre os 15 e os $19 \mathrm{~cm}$ ) (Fig. 5).

Apesar de a sua nomenclatura ter uma conotação funcional, o facto de nem sempre ser evidente a sua distinção das panelas aconselha a que seja entendido, no presente contexto, como contentor ambivalente e multifuncional.

Neste tipo presencia-se a modelação manual em $89 \%$ dos casos, conjuntamente com o fabrico de qualidade mediana (93\%). O tratamento superficial resume-se a alisamento, registando-se, por vezes (21\%), um alisamento cuidado no exterior e no dorso do bordo.

Assinala-se uma preponderância do modelo de perfil em S, com bordos extrovertidos em curva contínua, com colo contra-curvado e lábios boleados. Identificam-se ainda variações ao nível do desenho dos bordos, observando-se exemplares com bordo pouco esvasados com lábio plano; colos estrangulados ou, excepcionalmente, bordo em aba horizontal com lábio plano.

Trata-se de uma forma amplamente difundida em contextos da II Idade do Ferro, com paralelos regionais em Conímbriga (Alarcão, 1974, Est. II, n. ${ }^{\circ} 25$ e Est. III, 39-46), Santa Olaia (Rocha, 1908, Est. XXI, nos 68 e 70) Tavarede (Neves, 2013, Est. I) e Chões (Pereira, 1993, Est. III, 16).

Este é um formato "clássico" e recorrente no repertório cerâmico dos povoados da Idade do Ferro, especialmente no Noroeste e nas suas zonas de influência, pelo que se dispensa a enumeração de paralelos mais longínquos.

Conimbriga, 50 (2011) 33-57 


\section{Tipo II (Pequeno pote)}

Esta categoria formal assume um desenho análogo à anterior, distinguindo-se daquela pelas menores dimensões (diâmetro do bordo entre 10 e $13 \mathrm{~cm}$ ) (Fig. 6).

É a segunda forma mais registada, com 23 peças, $44 \%$ das quais modeladas manualmente e $26 \%$ ao torno - nas restantes o polimento impossibilita a identificação. A maioria das peças $(61 \%)$ revela fabricos finos, assinalando-se igualmente fabricos medianos (30\%) e grosseiros (9\%). Este é o formato mais registado entre os fabricos finos, atestando-se os tipos FA (n ${ }^{\text {os }} 2$ e 3$), \mathrm{FB}\left(\mathrm{n}^{\text {os }} 4\right.$ e 5$)$ e FE $\left(n^{\circ} 6\right)$.

Observa-se alguma variação ao nível do desenho de perfis, assinalando-se bordos extrovertidos e em aba oblíqua, colos rectos a contra-curvados, mais ou menos desenvolvidos e bojos globulares a elipsoidais. Nota-se igualmente uma tendência dentro dos fabricos finos para apresentarem bordos mais desenvolvidos e colos mais diferenciados.

A identificação de fragmentos de pequenas asas de seç̧ão circular em fabricos de tipo FA e FB bem como um bordo com arranque de asa de fabrico FB indicia que algumas destas peças seriam asadas correspondendo portanto a púcaros.

$\mathrm{O} \mathrm{n}^{\circ} 4$ assemelha-se à forma 4 , em cerâmica cinzenta fina polida, de Santarém (Arruda, 2000, Est. 57, 2), contando igualmente com paralelo em Conímbriga (Arruda 1997, fig. 6, 2) e ainda em Santa Olaia, com peça datada dos séc. VI-V a.C. (Pereira, 2009, Fig. 39, no 20 ).

Na mesma estação assinala-se um potinho em cerâmica fina atribuído aos séc. IV-III a.C. a que se assemelha o $\mathrm{n}^{\circ} 5$ inclusive no que se refere ao ligeiro ressalto na ligação entre colo e ombro.

Para o $\mathrm{n}^{\mathrm{o}} 6$ conhece-se uma peça idêntica em Viseu (Almeida, 2005, Est. XXV, 5).

Em cerâmica cinzenta fina registam-se recipientes semelhantes em Santa Olaia (Rocha, 1908, $n^{\circ}$ 119). Para a cerâmica manual, surgem peças afins no Crasto de Tavarede (Rocha, 1908, Est. XXXV, 384) e Conímbriga (Alarcão, 1974, Pl. II, 5 e 6).

Em Santarém esta forma (em cerâmica cinzenta fina) desenvolve-se apenas a partir dos níveis médios, assumindo uma presença mais significativa nos finais da Idade do Ferro. De igual modo, este grupo acusa uma presença relevante nas produções registadas em Santa Olaia, sobretudo durante a II Idade do Ferro - séc. IV-III a.C. (Pereira, 2009, 76).

Conimbriga, 50 (2011) 33-57 
Entre os recipientes deste formato destaca-se uma peça muito possivelmente de importação. Trata-se de um pequeno pote de bordo extrovertido (10,5 cm de diâmetro) com lábio boleado e colo pouco desenvolvido contra-curvado $\left(\mathrm{n}^{\circ} 1\right)$. A pasta é homogénea e dura com fraca distinção visual dos e.n.p. (mica), de coloração bege com cerne rosado. As superfícies encontram-se erodidas, ostentando pintura em tom de vermelho acastanhado no dorso do bordo e ombro associada a polimento. Para esta peça assinala-se paralelos em Conímbriga (Alarcão, 1974, II, 6-10; Correia, 1993, 253-254) e com os "vasos ovóides" de Santa Olaia (Pereira, 1997, fig. 120). De acordo com A. Arruda (2000, 7-24), e atendendo à curvatura do colo, será de admitir para este artefacto uma cronologia dentro do séc. VI a. C.

\section{Tipo III (Grande pote)}

Este tipo é formalmente similar aos precedentes, salvaguardando-se a superioridade do seu volume (com diâmetros de abertura entre os 23 e os $31 \mathrm{~cm}$ ). Pela dimensão, estes recipientes destinam-se ao armazenamento de víveres ou líquidos (Fig. 7).

Todos os exemplares detectados (13 NMI) são modelados manualmente, com fabricos medianos ( $77 \%$ ) e menos frequentemente grosseiros $(23 \%)$ e possuem superfícies alisadas.

A diversidade morfológica dentro desta categoria é assinalável, distinguindo-se recipientes de grande capacidade, bojudos de colo incipiente e bordo em aba horizontal; recipientes ovalados de bordo extrovertido com espessamento interno; peças esvasadas com colo contracurvado.

Verifica-se uma tendência para o aparecimento de demarcações internas na zona do bordo e colo, que marcam quebras de orientação da linha de perfil, eventualmente relacionadas com o encaixe de tampas.

Reconhecem-se contentores semelhantes em Viseu (Almeida, 2005, Est. XII, 4), Conímbriga (Alarcão, 1974, Pl. II, 12 e 14), Tavarede (Neves, 2013, Est. III, 12-A-540) e Santa Olaia (Pereira, 2009, fig. 44) no contexto da II Idade do Ferro.

Conimbriga, 50 (2011) 33-57 


\section{Tipo IV (Taça)}

Esta categoria engloba recipientes abertos de média dimensão (18 a $22 \mathrm{~cm}$ de diâmetro). O número de taças identificado é manifestamente reduzido (3) face aos restantes tipos.

Duas das peças enquadram-se no fabrico FB enquanto o $\mathrm{n}^{0} 3$ corresponde a um recipiente manual de fabrico mediano.

Pelo que é dado observar, registam-se modelos formais diferenciados, incluindo uma taça de bordo extrovertido demarcado internamente com incisão, uma segunda com bordo em aba descaída e outra de paredes côncavas divergentes com lábio boleado (Fig. 8).

Para o $\mathrm{n}^{\mathrm{O}} 3$ alistam-se paralelos formais em Santa Olaia - séc. VII-V (Pereira, 2009, fig. 35, n²5) e Conímbriga - II metade do I milénio (Arruda, 1997, fig. 5,1).

$\mathrm{O} \mathrm{n}^{\circ} 1$ poderá revelar alguma afinidade com prato em cerâmica cinzenta fina polida de Chões (Pereira, 1993/4, Est. IV, 28) ou mesmo com peça de Santa Olaia do período de transição - séc. VI-V a.C. (Pereira, 2009, fig. 41, nº 45).

\section{Fundos}

Considerados como uma componente menos elucidativa do ponto de vista informativo, os fundos merecem todavia uma referência pelas características reveladas. Os exemplares identificados possuem um diâmetro inscrito entre os 5 e os $16 \mathrm{~cm}$. No que respeita à tipologia formal cerca de metade dos indivíduos (51\%) possui fundo de base plana, $38 \%$ apresentam fundo plano espessado exteriormente, $9 \%$ mostram fundo côncavo e 4\% fundo em pé anelar.

Dentre as peças apresentadas destaca-se o $\mathrm{n}^{\circ} 1$, uma peça de fabrico FA singular por ostentar a superfície externa da base polida (Fig. 9).

\section{Decoração}

Como foi referido, a ocorrência de decoração é pouco expressiva, equivalendo a $1 \%$ da amostra. Os processos ou técnicas decorativas detectadas circunscrevem-se à incisão e aplicação de estampilhas (Fig. 10).

Conimbriga, 50 (2011) 33-57 
No caso da incisão, embora a reduzida dimensão dos fragmentos não permita identificar integralmente os padrões representados, estes estruturam-se em faixas formadas por sequências de segmentos de recta podendo compor reticulados, sequências simples com base em linhas de orientação diagonal ou padrões mais complexos. Em termos técnicos, os exemplares apresentam incisões pouco profundas executadas com instrumento de ponta romba sobre recipientes modelados manualmente.

Para os motivos estampilhados registam-se duas tipologias distintas: a aplicação de matrizes de contorno triangular em fragmentos de modelação manual e a impressão de linhas de pontilhados por meio de roleta sobre uma peça montada ao torno $\left(\mathrm{n} .^{\circ} 7\right)$.

$\mathrm{O}$ conjunto apresentado enquadra-se nos ambientes da segunda Idade do Ferro do Ocidente Peninsular.

Relativamente às matrizes, registam-se, para os $n^{\circ} 5$ e 6 , motivos semelhantes tanto no sul do país, concretamente em Garvão (Beirão et al., 1985, Fig. 27), como no centro-norte, em Romariz (Silva, 2007, Est. LXIX, 613 e 616).

\section{Nota final}

Não será despiciendo repetir que o quadro tipológico apresentado reflecte tão-somente o perfil deste lote em concreto, sendo arriscado entendê-lo como representativo da realidade artefactual mais lata em que se integra - a do povoado. O presente objectivo é fornecer uma perspectiva inaugural das produções cerâmicas da II Idade do Ferro de Coimbra, sendo com expectativa que se aguardam novos contributos para o tema. A descrição pormenorizada das cerâmicas em termos morfológicos, técnicos e estilísticos aqui fornecida justifica-se, exatamente, por ser esta a primeira vez que se disponibiliza, entre a comunidade científica, inequívoco conjunto ceramológico da ocupação proto-histórica do lugar de Coimbra.

Feita a ressalva, pretende-se destacar deste trabalho algumas ideias dominantes. Antes de mais, e salvo dois exemplos de cerâmica orientalizante importada, o material estudado deverá, presumivelmente, dimanar de um centro de produção local ou regional, (como aponta a matriz das pastas). A mesma tendência de proveniência local dos artefactos cerâmicos, onde se incluem peças de luxo e semi-luxo, já se verificara igualmente em Conímbriga (Alarcão, 1974), Santa Olaia

Conimbriga, 50 (2011) 33-57 
(Cabral et allii, 1983) ou até mesmo em Lisboa (Sousa, 2011: 213) o que parece apontar para um padrão, aparentemente generalizado na zona centro litoral, de acomodação sobretudo a um sistema de autoconsumo.

Assinala-se aqui a presença de uma produção marcadamente indígena pautada por contentores de armazenamento e cozinha, contemplando ainda um segmento mais requintado, ligado a recipientes de consumo, conjugando modelos formais eminentemente indígenas com alguns traços de inspiração orientalizante ou helenizante.

O primeiro grupo referido engloba os potes e grandes potes de perfil simples, regra geral produzidos manualmente. Refira-se como único traço de originalidade destes recipientes a ostentação de fundos demarcados por depressão e toro ou simplesmente reforçados exteriormente. Note-se que os exemplos de decoração incisa e estampilhada encontrados relacionam-se com este grupo (pelos fabricos e espessura das paredes), característica que tem sido conotada com componentes de matriz continental ou "celtizante".

Já para o segundo grupo (onde se inscrevem os pequenos potes e taças) poder-se-á discernir um ascendente de influência meridional. Caso disso é a associação do fabrico FA a cerâmicas ditas helenísticas de verniz negro e do fabrico FB às cerâmicas cinzentas finas.

No primeiro caso (fabricos FA) parece constatar-se um fenómeno de sincretismo e mimetização selectiva. Ou seja, a aptidão para o consumo de cerâmicas de verniz negro (profundamente difundidas por todo o mediterrâneo através do bucchero Etrusco e Eólio, das produções áticas, da Apúlia, da Câmpania, da Lucania e Sicília e das produções do Meio-dia peninsular e norte africanas "tipo Kuass") levou, crê-se, à tentativa de imitação generalizada e incorporação de determinadas características estilísticas destes objectos por parte dos oleiros indígenas (Niveau, 2008: 131-132). Neste caso em particular, a ostentação de superfícies com engobes untuosos de coloração negra uniforme associadas certamente a um serviço de mesa de aspiração sumptuária. Este fenómeno, enquadrado no conceito das produções protocampanienses, deve ser entendido na óptica da "explosão" de centros produtores de carácter local e regional que eclodem por todo o Mediterrânio e procuram suprir através da imitação, as cerâmicas helénicas após a sua entrada em declínio em finais do séc. VI a. C. (Adroher Auroux e López Marcos, 1995: 24).

Relativamente à cerâmica cinzenta fina polida, o mesmo tipo de produção eminentemente local desta cerâmica de carácter semi-luxuoso

Conimbriga, 50 (2011) 33-57 
já havia sido identificado e comprovado em Conímbriga, Santa Olaia e Lisboa, onde a composição química das pastas revelou o fabrico destes produtos com recurso a barreiros locais diferenciados (Cabral et alii, 1983). A par disso, encontra-se igualmente demonstrada a existência de intercâmbio destes produtos quer entre povoados produtores e não produtores (Conimbriga/Tavarede), quer entre centros produtores dentro da mesma região (Conimbriga e Santa Olaia) ou entre regiões afastadas (Santa Olaia e Lisboa) (Alarcão e Correia, 1994: 101).

Em resumo, da apreciação global do conjunto artefactual, salienta-se, à falta de melhor designação, a acentuada matriz indígena, marcada pela simplicidade e monotonia formal dos recipientes e pelo tipo de ornamentação estampilhada e incisa. Este cunho indígena aparece todavia temperado por reflexos inovadores assinalados pela absorção selectiva de influências mediterrâneas, nomeadamente dos círculos da cerâmica de verniz negro. Neste sentido, reconhecer, pela primeira vez, indícios deste fenómeno em concreto, numa área tão setentrional, é decididamente um factor de redobrado interesse.

A comprovar-se a tendência observada ao nível dos modelos morfológicos, relacionada com a predilecção por formas fechadas em oposição às abertas, esta deverá merecer alguma reflexão. A este propósito, é interessante verificar que na proximidade, em Santa Olaia, a transição da I para a II Idades do Ferro é marcada pela significativa diminuição das formas abertas relativamente às fechadas que passam a predominar (Pereira, 2009). É de crer que, da mesma forma, em Coimbra, haja ocorrido o mesmo processo, cuja raiz se prende, eventualmente, com o padrão de hábitos de consumo registado à data, ou com a diminuição da importação de peças que, por imposição prática, são preferencialmente abertas, por serem mais facilmente empilháveis.

A este propósito, é oportuno lembrar que esta tendência pela escassez de formas abertas e o domínio das fechadas já se esboçava no final do séc. V a.C., em Lisboa (Sousa, 2011). Esta situação parece ser, assim, muito própria da fachada atlântica ocidental peninsular face ao Algarve, onde o domínio das tigelas é absoluto e esmagador (Sousa e Arruda, 2010).

Sustentando uma primeira tentativa de datação destas peças no estabelecimento de analogias e paralelos por comparação tipológica com os conjuntos mais próximos aponta-se, em termos abrangentes, a segunda metade do I milénio a. C. (finais dos sécs. IV/III a.C.) para a inscrição destas produções.

Conimbriga, 50 (2011) 33-57 
A ser desta forma, é interessante observar como estes vestígios se reportam a um período de enfraquecimento ou de contracção dos contactos com o sul peninsular e o mundo mediterrâneo, sem que, todavia, estes se esgotem totalmente (Arruda, 2005). Esta tendência é apontada para este território regional em concreto com base nos exemplos de Conímbriga (Arruda, 1997: 23) e Santa Olaia (Pereira, 1996: 63). No caso desta última, observa-se mesmo uma fase de decadência precisamente na transição do século $\mathrm{V}$ para o IV a. C.

Contrariamente a estes sítios, em Coimbra, os escassos dados disponíveis não permitem, de modo algum, calcular o posicionamento deste povoado no contexto regional e concretamente face à diminuição destes estímulos mediterrâneos de natureza fenícia ou turdetana (Almagro-Gorbea et alii, 2009). Conquanto não deixa de ser sugestivo equacionar a produção de determinadas cerâmicas finas (nomeadamente as de superfície negra) como compensação e contrapartida face à diminuição do acesso a bens importados. Dito de outro modo, a escassez de determinados produtos exógenos e mais concretamente de cerâmicas de verniz negro estimularia a tentativa da sua reprodução local.

O mesmo evento de atomização deste tipo de produções (de recipientes de mesa finos) encontra-se mais bem documentado para o que convencionalmente se designa de "Círculo do Estreito" onde a investigação tem vindo a revelar, no contexto do séc. III a. C., um mundo fragmentado e autossuficiente, caracterizado pela profusão de oficinas que tentam responder às profundas mudanças e convulsões que acompanham o desaparecimento da cerâmica grega em finais do séc. VI a.C. (Niveau, 2003: 23).

Em síntese, no que toca a Coimbra ou melhor dizendo Aeminium, esta é uma manifestação ainda muito mal compreendida, que é imperioso aprofundar, por forma a mais claramente nela se descortinar os reflexos do seu tecido socio-económico, tendencialmente relegado, no contexto da II Idade do Ferro, pela conjecturada marginalidade territorial. Marginalidade esta que se suspeita potenciar o desvinculamento dos padrões veiculados no eixo do Mediterrâneo, concorrendo para a individualização do perfil cultural deste Oppidum, na longínqua fachada Atlântica. Ir mais além na senda das comunidades pré-romanas de Coimbra, no seu contexto regional e inter-regional, é caminho que está ainda por fazer.

Conimbriga, 50 (2011) 33-57 


\section{BIBLIOGRAFIA}

Adroher Auroux, Antonio Maria; LOPEZ MARCOS, Antonio (1995), Las cerámicas de barniz negro. I. Cerámicas áticas y protocampanienses, Florentia Iliberritana, 6: 11-53.

Almagro-Gorbea, Martín; Torres Ortiz, Mariano (2009), La colonización de la costa atlântica de Portugal: fenícios o tartesios?, Paleohispanica, 9: 113-142.

Alarcão, Adília, Correia, Virgílio, H. (1994), Cerâmicas comuns da Idade do Ferro de Conimbriga. In Idade do Ferro (catálogo da exposição), Figueira da Foz, Museu Municipal: 99-102.

AlarCão, Jorge de (1974), Cerâmica comum local e regional de Conimbriga, Coimbra.

Alarcão, Jorge de (2008), Coimbra. A montagem do cenário urbano. Coimbra. Imprensa da Universidade de Coimbra.

Almeida, Sara (2005), A Idade do ferro no planalto de Viseu - O caso do Morro da Sé. Dissertação de mestrado apresentada à FLUC, policopiado.

Arruda, Ana M. (1997), Conimbriga: Fouilles de 1988-89. 2. Les travaux sur le forum. In Itinéraires Lusitaniens. Paris. Diffusion Boccard: 13-33.

Arruda, Ana M. (2000), Fenícios e mundo indígena no centro e Sul de Portugal (séculos VIII-VI a. C.) em torno às histórias possivveis. 2 vols. Lisboa: Faculdade de Letras da Universidade de Lisboa (Dissertação de Doutoramento, policopiada).

Arruda, Ana M., (2005), O $1^{\circ}$ milénio a.n.e. no Centro e no Sul de Portugal: leituras possíveis no início de um novo século. O Arqueólogo Português, série IV, vol. 23: 9-156.

Beirão, Caetano M., Silva, Carlos T., Soares, Joaquina, Gomes, Mário V., Gomes, Rosa, V. (1985), O Arqueólogo Português, série IV, vol. 3: 45-136.

Cabral, J. M. P., Gouveia, M. A.; Alarcão, A. M.; Alarcão, J. (1983), Neutron activation analysis of fine grey pottery from Conímbriga, Santa Olaia and Tavarede, Portugal, Journal of Archaeological Science, 10: 61-70.

Carvalho, Pedro (1998), O Forum de Aeminium, Coimbra, Instituto Português de Museus.

Correia, Virgílio H. (1993), Os materiais pré-romanos de Conímbriga e a presença fenícia no baixo vale do Mondego, Estudos Orientais, 4: 229-283.

FILIPE, Sónia (2006), Arqueologia urbana em Coimbra: um testemunho da Reitoria da Universidade, Conimbriga, 45: 337-357.

Frade, Helena, Caetano, José C., (1994), O pátio da Inquisição (Coimbra): notas histórico-arqueológicas, Bracara Augusta: Revista de Arqueologia Urbana, 45: 319-343.

Mantas, Vasco (1983), Alcáçova de Coimbra, Informação Arqueológica, 3: 31.

MANTAS, Vasco (1992), Notas sobre a estrutura urbana de Aeminium, Biblos, 68: 487-513.

Margarido, Ana Paula (1987), A Morfologia urbana da "Alta" de Coimbra - Ensaio sobre o traçado da malha e sua evolução. Cadernos de Geografia. IEG. Coimbra, vol. 6: 43-69.

Neves, Sílvia Gonçalves (2013), O Crasto de Tavarede (Figueira da Foz) no quadro das problemáticas da I Idade do Ferro no Baixo Mondego. Dissertação de mestrado apresentada à FLUC, policopiado.

Conimbriga, 50 (2011) 33-57 
Niveau De Villedary Y Mariñas, Ana Maria (2003), Las Cerámicas Gaditanas “Tipo Kuass”. Bases para el análisis de la Bahía de Cádiz en época púnica. Biblioteca Archaeologica Hispana 21. Studia Hispano-Phoenicia 4. Madrid: Real Academia de la Historia- Universidad de Cádiz.

Niveau De Villedary Y Mariñas, Ana Maria (2008). La cerámica "Tipo Kuass". In D. Bernal y A. Ribera (Eds.), Cerámicas hispanorromanas. Un estado de la cuestión, Servicio de Publicaciones de la Universidad de Cadiz. Cádiz: 245-262.

Pereira, Isabel (1993), Figueira da Foz, Santa Olaia, Estudos Orientais, 4: 295-304.

Pereira, Isabel (1993-1994), Casais agrícolas da Idade do Ferro na Foz do Mondego - Figueira da Foz, Conimbriga, 32-33: 75-85.

Pereira, Isabel (1996), "Santa Olaia", In De Ulisses a Viriato - O primeiro milénio a.C. Lisboa: Instituto Português de Museus: 118-133.

Pereira, Isabel (1997), Santa Olaia et le commerce atlantique. In Itineraires Lusitaniens. Paris. Diffusion de Boccard: 209-253.

Pereira, Isabel (2009), As actividades metalúrgicas na I. ${ }^{a}$ Idade do Ferro em Santa Olaia - Figueira da Foz, Conimbriga, 48: 61-79.

Rocha, António dos Santos (1904-8), Memórias e explorações arqueológicas II. Estações pré-romanas da Idade do Ferro nas vizinhanças da Figueira. Portugália, 2: 302-256.

Silva, Armando Coelho (2007²), A cultura castreja no Noroeste de Portugal, Paços de Ferreira.

Sousa, Elisa (2011), A ocupação pré-romana na foz do Estuário do Tejo durante a segunda metade do $1^{\circ}$ milénio a.C. Tese de doutoramento apresentada à Faculdade de Letras da Universidade de Lisboa (policopiada).

Sousa, Elisa, Arruda, Ana Margarida (2010), A Gaditanização do Algarve. Mainake, 32 (2): 951-974.

Conimbriga, 50 (2011) 33-57 


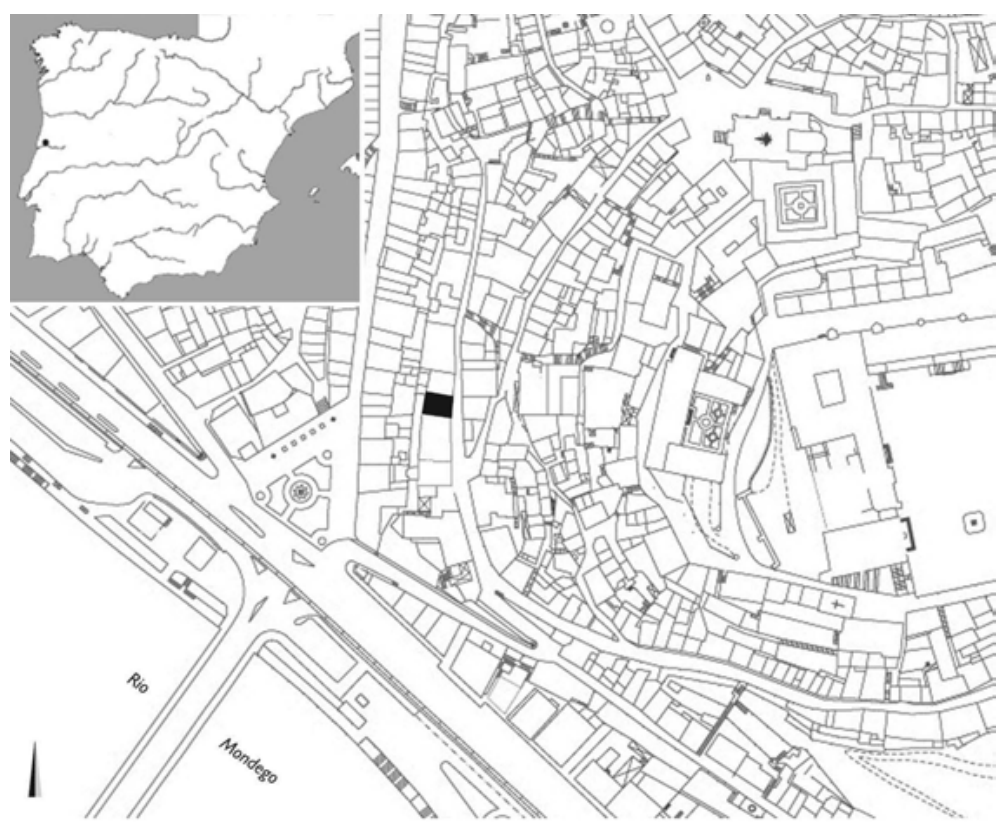

FIG. 1 - Localização da intervenção na planta da cidade.

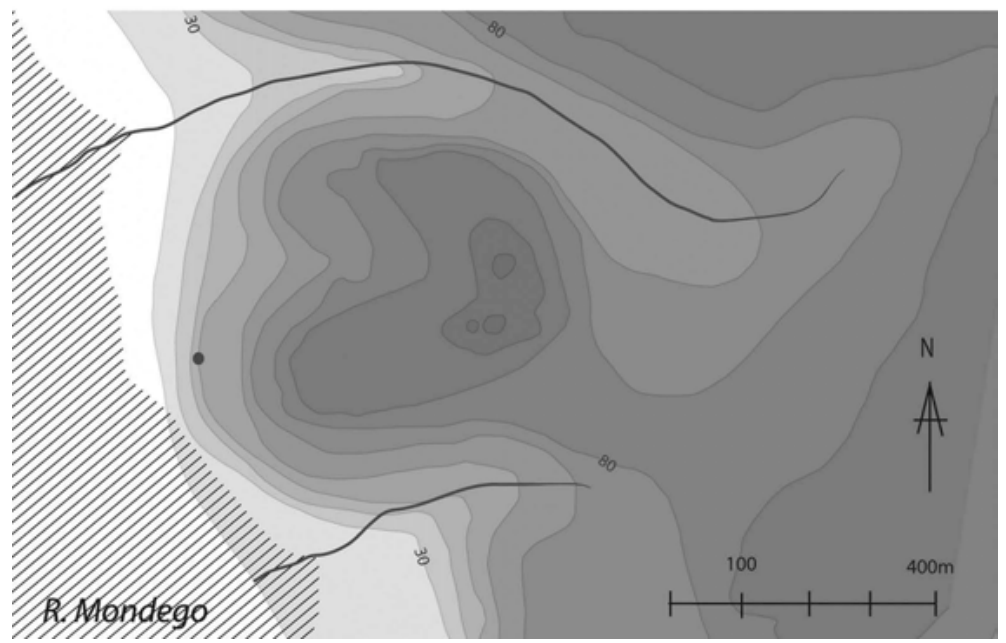

FIG. 2 - Localização da intervenção na planta topográfica da colina genética. 

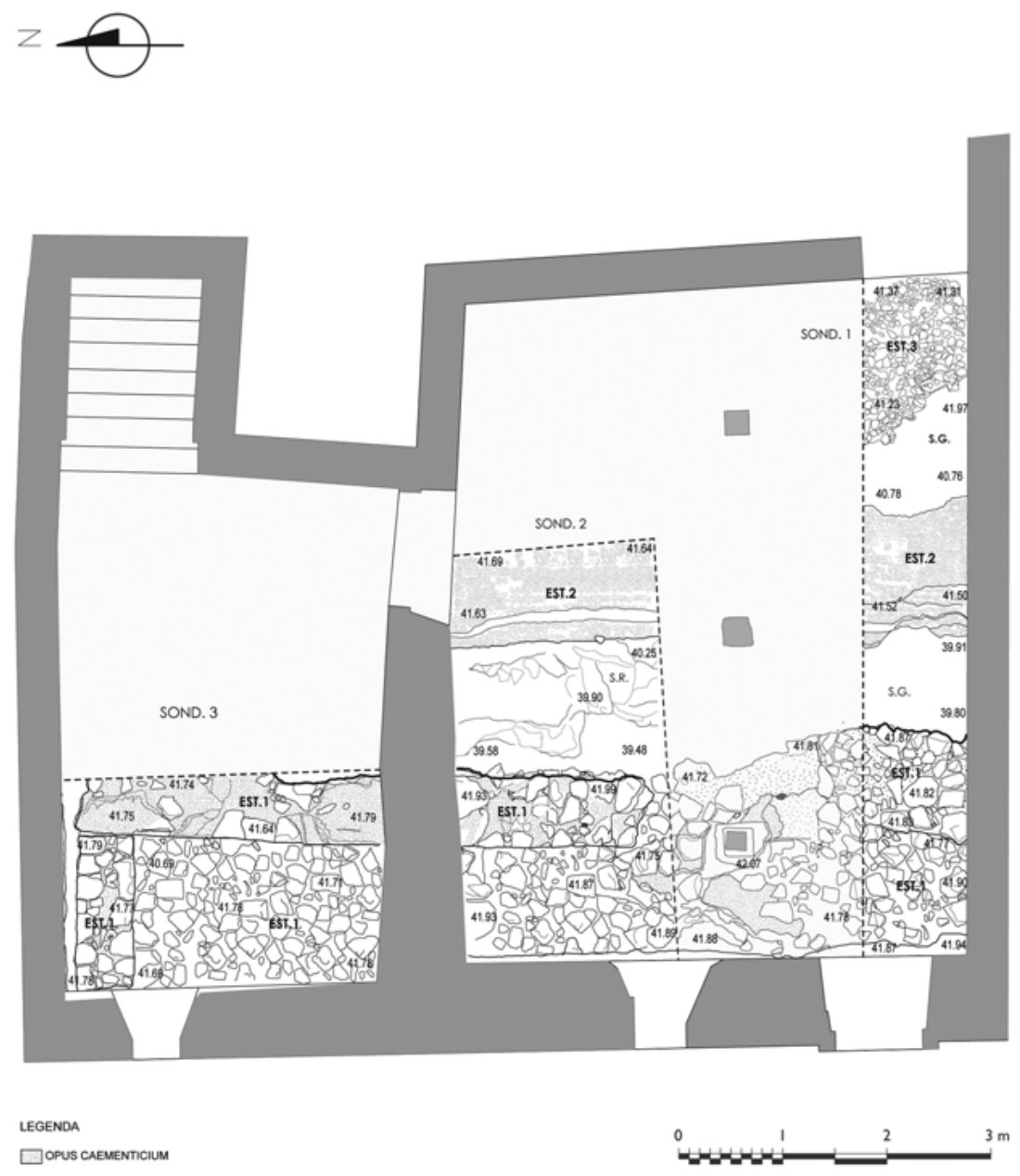

FIG. 3 - Plano final da intervenção com indicação das sondagens. 


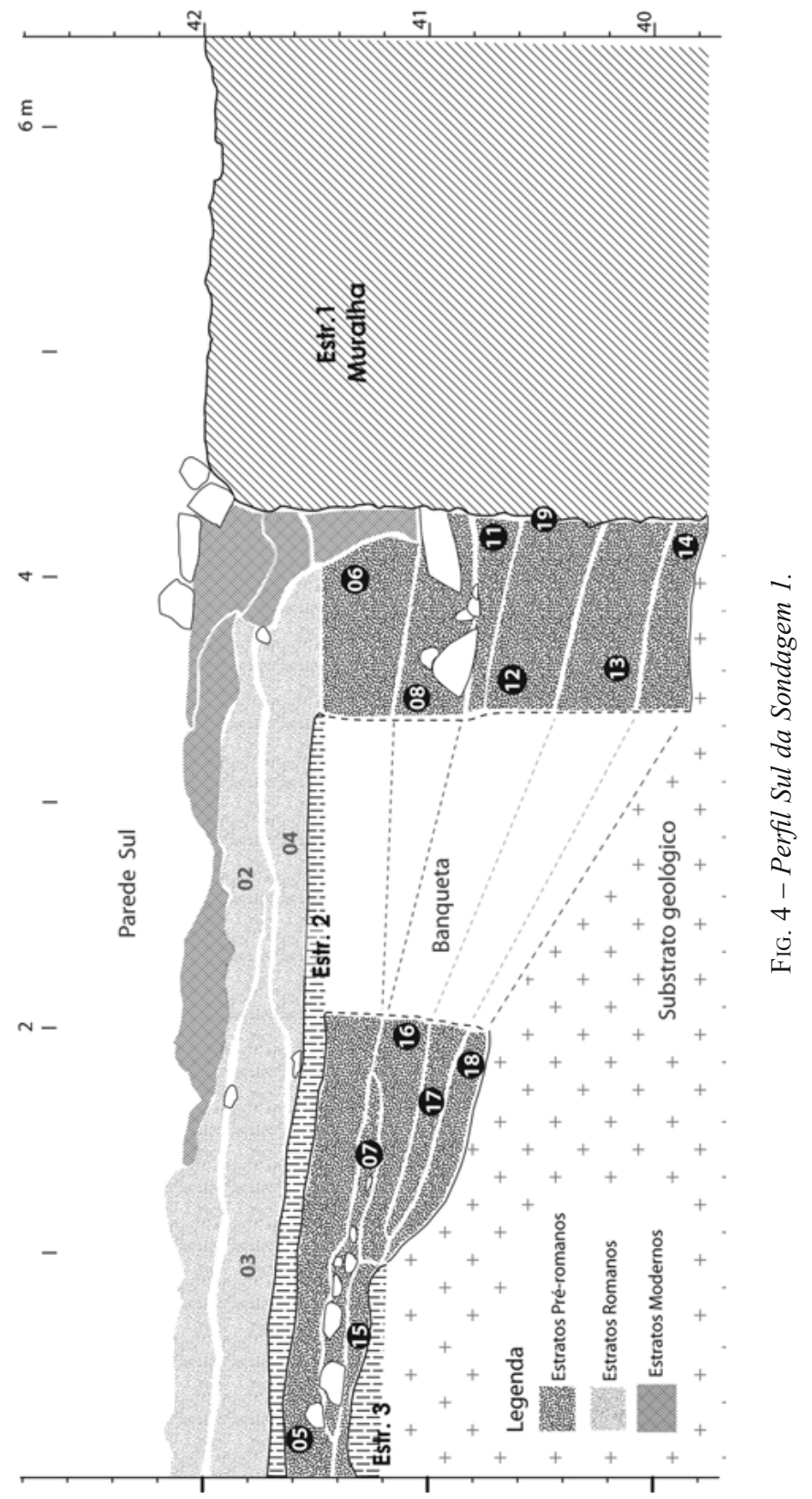



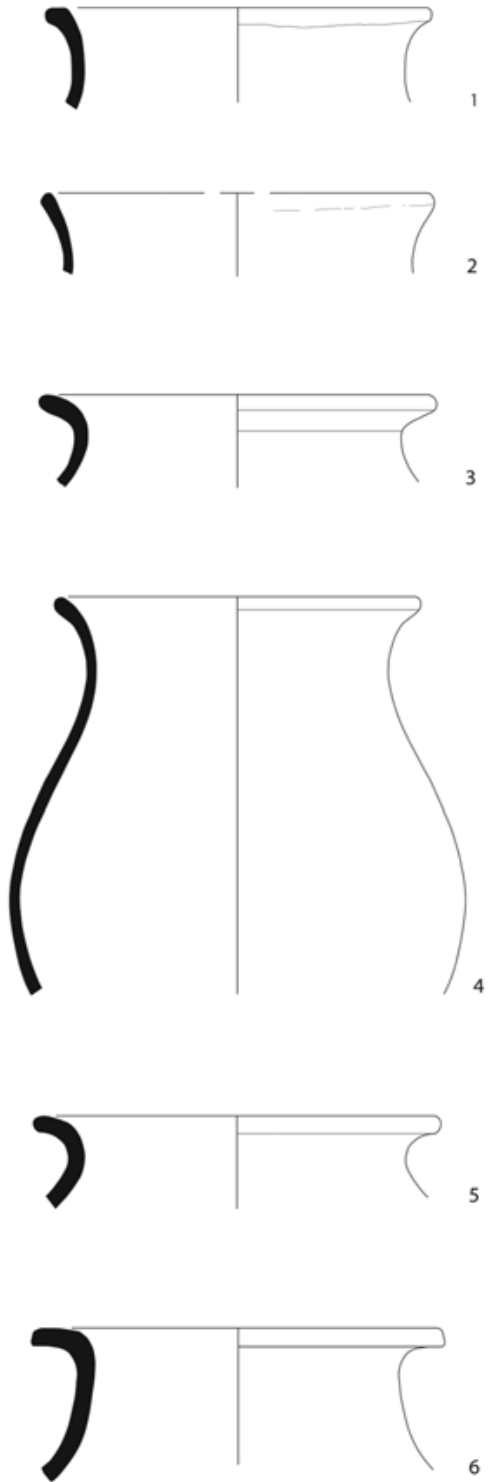

$0.5^{\mathrm{cm}}$

Fig. 5 - Potes. 

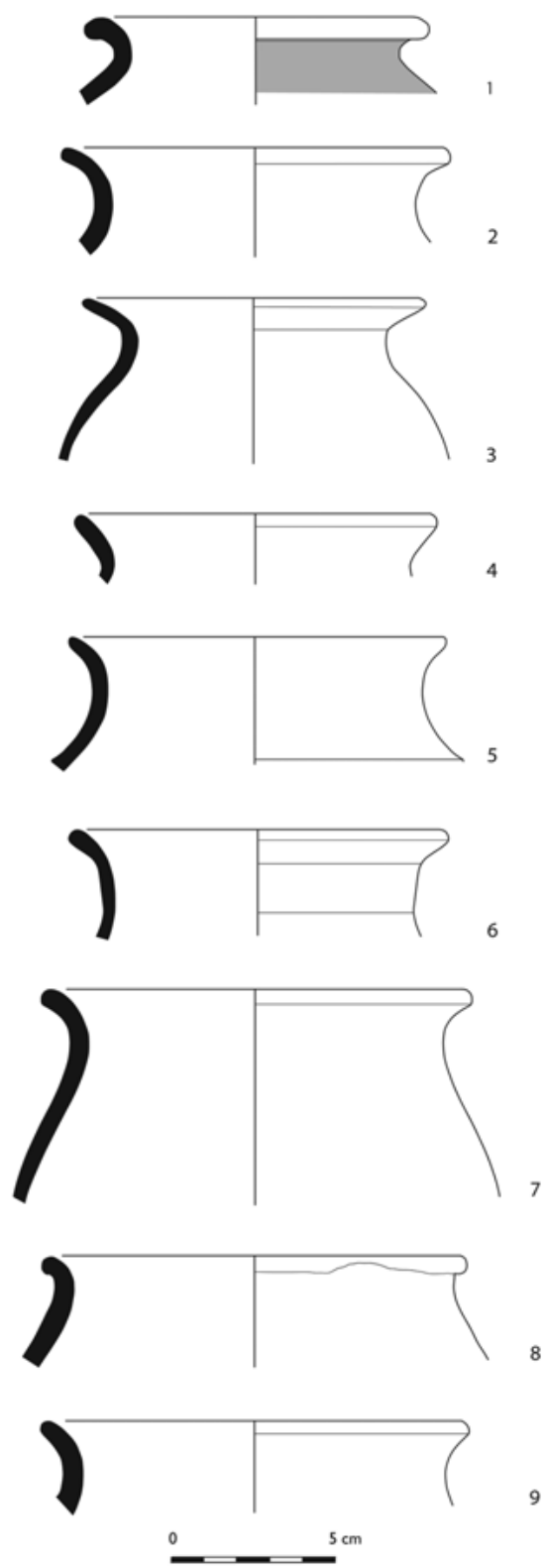

FIg. 6 - Pequenos potes. 

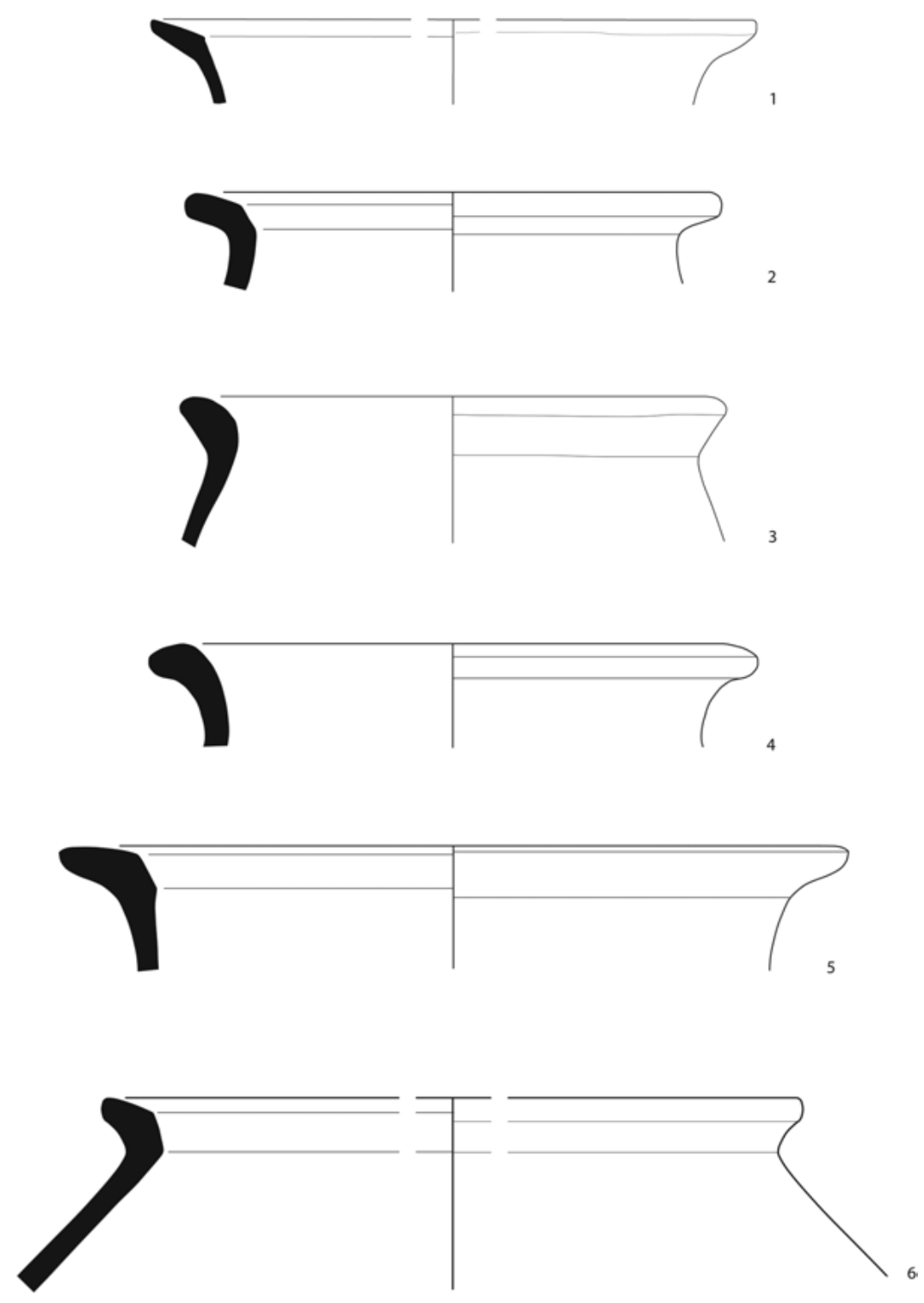

$$
\text { - }-^{\mathrm{cm}}
$$

FIG. 7 - Grandes potes. 

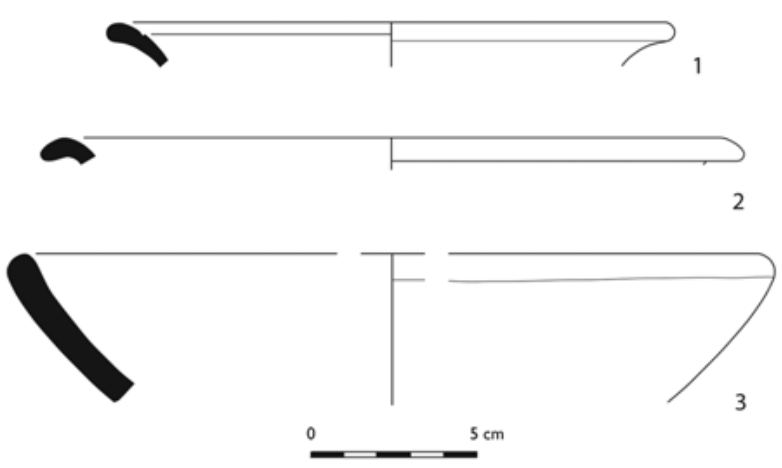

FIg. 8 - Taças.
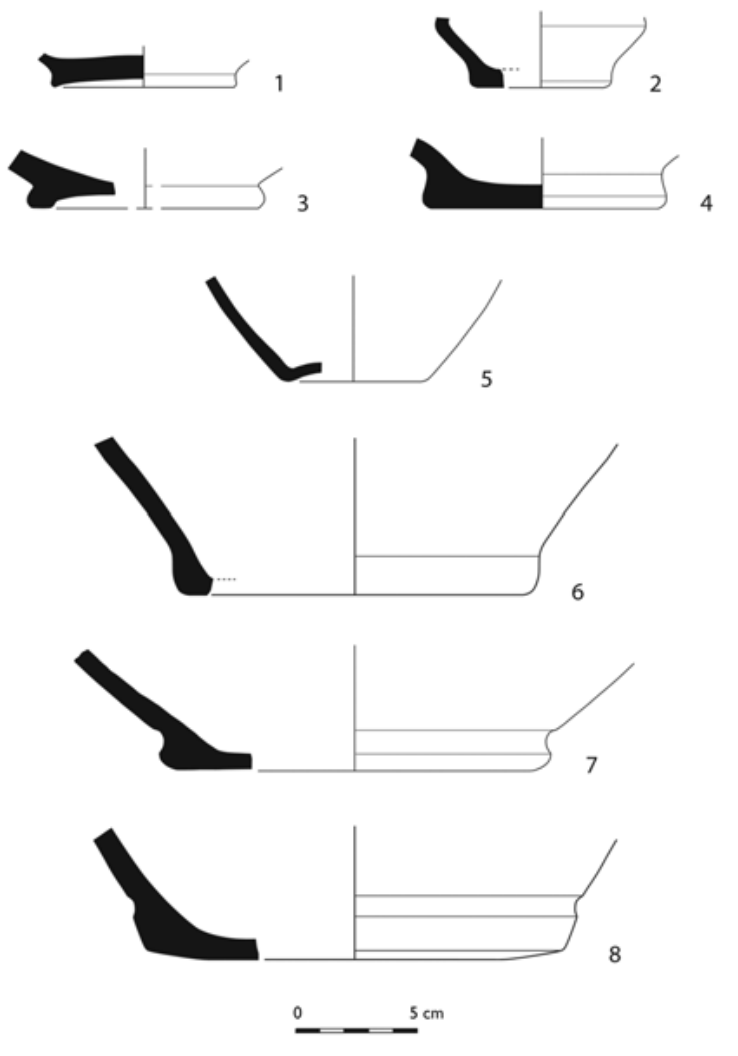

FIG. 9 - Fundos. 

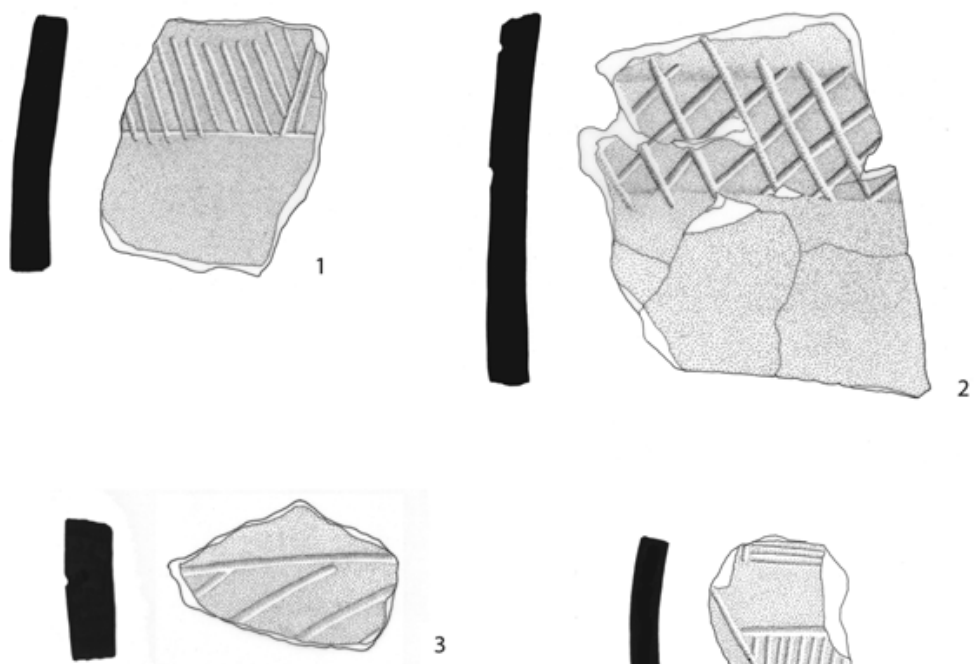

3
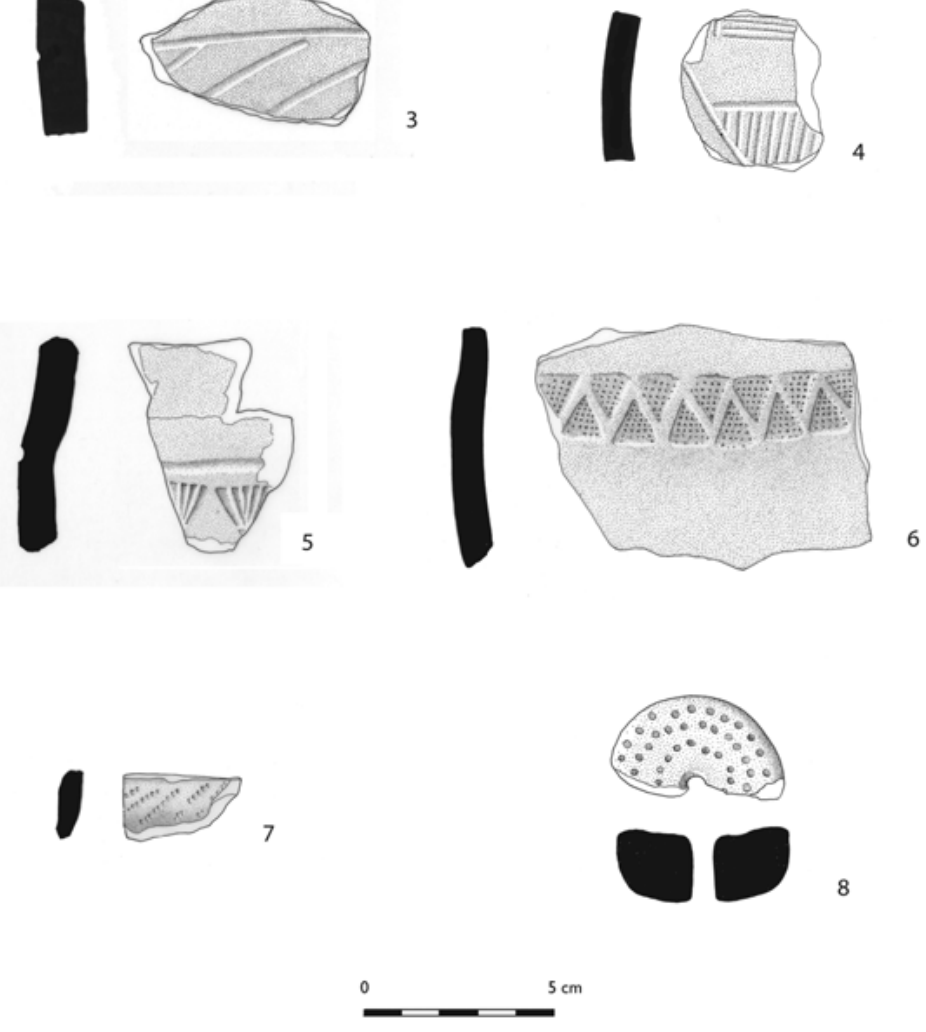

FIG. 10 - Fragmentos decorados. 